Original Research

\title{
Public knowledge, beliefs, psychological responses, and behavioural changes during the outbreak of COVID-19 in the Middle East
}

\author{
Husam ABAZID* ID, Iman A. BASHETI* (D), Esraa E. AL-JOMAA (D), Ayham ABAZID ID, Warda M. KLOUB ID. \\ Received (first version): 30-Jan-2021 Accepted: 16-May-2021 Published online: 25-May-2021
}

\begin{abstract}
Objective: To evaluate the knowledge, believes, psychological and behavioural impact of COVID-19 on the general population in the Middle East, exploring how it impacted public lives.

Methods: A descriptive cross-sectional online survey was sent to a convenience sample in the Middle East through social media (Facebook and WhatsApp) between $16^{\text {th }}$ of June and $30^{\text {th }}$ of June 2020. The questionnaire was designed to collect the demographic, participant's source of information regarding COVID-19, knowledge and believes about COVID-19, the psychological consequences of COVID-19, impact of COVID-19 on participant's behaviour. The final version of the questionnaire was further tested for content validity by experts in the field.

Results: A total of 2,061 participants completed the survey, with the majority being females ( $n=1394,67.6 \%$ ), from urban areas $(n=1896,92 \%)$ and the majority were from countries of The Levant $(n=1199,58.1 \%)$, followed by the Arabian Peninsula $(n=392,19.1 \%)$, Iraq $(n=300,14.6 \%)$ and Egypt $(n=138,6.7 \%)$. Few participants (3.0\%) reported to have been infected and many ( $n=1847,89.6 \%)$ were committed to quarantine at home. Social media platforms were the most common sources of information (41.2\%). Many (63\%) believed that COVID-19 is a biological weapon and were afraid of visiting crowded places (85\%). The majority avoided public facilities (86.9\%) such as prayer places and believed that the news about COVID-19 made them anxious (49.5\%).
\end{abstract}

\section{Keywords}

COVID-19; Disease Outbreaks; Quarantine; Health Knowledge, Attitudes, Practice; Attitude to Health; Fear; Problem Behavior; Social Media; Surveys and Questionnaires; Cross-Sectional Studies; Middle East

\section{INTRODUCTION}

Coronavirus disease outbreak in 2019 (COVID-19) is an emerging respiratory disease caused by a novel coronavirus. ${ }^{1}$ COVID-19 was first detected in December 2019 in Wuhan, China. ${ }^{2}$ On January 30, 2020, the World Health Organization (WHO) declared that COVID-19 is a pandemic disease. ${ }^{3}$ Till this day, more than 149 million cases were reported globally and more than 3 million confirmed deaths. ${ }^{4}$

It is known that COVID-19 can spread to humans through an intermediate host such as bats, or from human-tohuman, through respiratory droplets and body contacts. ${ }^{1}$ Contact with contaminated surfaces, hands, and touching of the face, eyes, nose, and mouth are predominant ways to get exposed to the infected droplets. ${ }^{5}$ The main signs and symptoms of COVID-19 infection include fever, cough, and shortness of breath 6 . The incubation period of COVID19 infection is between 2-14 days after exposure. ${ }^{4}$ Preliminary data suggest that older adults and persons with

Husam ABAZID. PhD. Department of Clinical Pharmacy and Therapeutics, Faculty of Pharmacy, Applied Science Private University. Amman (Jordan).h_abazid@asu.edu.jo

Iman A. BASHETI. PhD. Department of Clinical Pharmacy and Therapeutics, Faculty of Pharmacy, Applied Science Private University. Amman (Jordan). dr_iman@asu.edu.jo

Esraa Ebraheem AL-JOMAA. Clinical pharmacist. Faculty of

Pharmacy \& Medical Sciences, University of Petra. Amman (Jordan). esraagomaa8@gmail.com

Ayham ABAZID. MD. Medical Department, King Fahad Specialist Hospital. Buraidah Al-Qasim (Saudi Arabia)

ayhamabazid@yahoo.com

Warda M. KLOUB. Educational leadership. University of Jordan.

Amman (Jordan). wardwwwkloub@gmail.com

${ }^{*}$ First co-authors underlying health conditions or compromised immune systems might be at greater risk for severe symptoms from this virus.

In the Middle East region, more than 2.5 million cases were reported until October $4,2020 .{ }^{4}$ COVID-19 has appeared in some countries more than others. Iran has reported the greatest number of cases, with more than 470,000 cases, followed by Saudi Arabia $(335,000$ cases) and Turkey $(323,000$ cases $) .^{4-8}$ Jordan witnessed a sudden increase in the number of cases during the past few months (October, 2020), recording more than 15,000 cases. ${ }^{4}$ Other countries such as Syria and Al Yemen have reported up to 5,000 cases at the time of writing of this manuscript. ${ }^{4}$ In order to suppress this pandemic, the co-operative work between each government and public is extremely vital to come up with an effective program to protect and prepare against COVID-19. Many studies have shown that practicing preventive measures on an individual level is effective in curbing the spread of infection, i.e. wearing a mask, washing hands, using a hand sanitizer, maintaining social distancing, and staying at home. ${ }^{3}$ On the other hand, the WHO released some mental health considerations that should be followed during this crisis, such as avoiding watching and listening to news constantly, staying connected with loved ones through digital media, reassuring and supporting each other, along with taking care of one's own health i.e. exercising, eating healthy, and sleeping well regularly. ${ }^{9}$

Public adherence to these control measures is associated with a level of emotional provocation among the population, the level of which is affected by their 
knowledge and beliefs about COVID-19. ${ }^{10,11}$ This in turn can affect the behavioural and psychological responses of the population. ${ }^{12,13}$ Hence, evaluating of public perceptions toward such outbreaks is essential, especially with the existence of the large amount of misconceptions and false information circulating around on social media regarding the transmission and methods of acquisition of COVID-19. ${ }^{14}$ Up to this day, there are several research articles globally and in the Middle East examining the psychological and behavioral impact and public perceptions of the pandemic. ${ }^{15-22}$ Such findings would provide public health officials with the needed data leading to policy updates regarding the management of the COVID-19 pandemic in the Middle East.

This study will evaluate the knowledge, beliefs and behavioural impact of COVID-19 pandemic on the general population in the Middle East, exploring how it impacted public lives.

\section{METHODS}

\section{Study design and population}

A descriptive cross-sectional online survey was conducted between the16th of June and 30th of June 2020 in sixteen countries in the Middle East. The countries included countries of the Levant, The Arabian Peninsula, Iraq, Egypt, Turkey and Iran.

\section{Questionnaire development and data collection}

Following an extensive literature review on published studies related to the COVID-19 pandemic, a draft questionnaire was designed to cover the areas of interest in this study. The questionnaire was written in two languages, English and Arabic. The translation was validated by the Translation Department at the Applied Science Private University (ASU) and followed the standard 'forwardbackward' procedure. The final version of the questionnaire was further tested for content validity by experts in the filed who gave their constructive suggestions, and positive feedback for the process. The final version of the questionnaire was organized into five main sections addressing different topics of interest to answer the aim of the study. The first section included items set to collect demographic data about participants' characteristics. The second section included multiple-choice questions about participant's source of information regarding COVID-19. The third section was planned to assess participant's knowledge and beliefs about COVID-19 pandemic. The fourth section was set to assess the psychological consequences of COVID-19 pandemic on the participants. Finally, the fifth section was set to assess the impact of COVID-19 on participant's behaviour and the safety procedures they followed to avoid getting infected by the COVID-19 virus. Internal reliability was assessed by measuring the Cronbach's alpha. For participant's knowledge and beliefs section internal consistency demonstrated high reliability (alpha=0.84), the psychological effect of COVID-19 section had an internal consistency of alpha $=0.62$, and the internal consistency for the behavioral impact of COVID-19 on participants section was alpha $=0.81$.

\section{Sampling strategy and sample size}

A convenience sample of eligible participants was invited to participate in the study from the sixteen countries included in the study through social media (Facebook and WhatsApp). The covering letter stressed anonymity and confidentiality and explained the aim and objectives of the study. Participants did not receive any benefits or payments for filling-out the questionnaire.

Inclusion criteria for the participants in the study included: Residents in Middle East, above 18 years old, and they have the ability to speak and write Arabic language. A consensus sample of subjects was included in the study. Based on the population size in the Middle East $(n=411,551,760)$, sample size calculation was conducted using a margin of error of $5 \%$, confidence level of $95 \%$, and response distribution of $50 \%$, giving a minimum sample size of 384 participants. A consensus sample of subjects was included in the study.

\section{Ethical approval}

This study was approved by the Research Ethics Committee at Faculty of Pharmacy at Applied Science Private University (ASU), Amman, Jordan (Approval No: 2020-PHA-25). The consent to participate was implied by the act of completing and returning the e-survey.

\section{Statistical analysis}

Data were analyzed by using the SPSS version 24 . The internal reliability was assessed by measuring the Cronbach's alpha for the survey. The descriptive analysis was performed using frequency/percentage for qualitative variables. Age variable was expressed as mean (SD).

\begin{tabular}{|c|c|}
\hline Age in years; mean (SD) & $27.5(22.4)$ \\
\hline \multicolumn{2}{|l|}{ Gender, n (\%) } \\
\hline Female & $1394(67.6)$ \\
\hline Male & $667(32.4)$ \\
\hline \multicolumn{2}{|l|}{ Accommodation place, $\mathrm{n}(\%)$} \\
\hline City & $1896(92)$ \\
\hline Countryside & $165(8)$ \\
\hline \multicolumn{2}{|l|}{ Country of residency, $\mathrm{n}(\%)$} \\
\hline Countries of the Levant & $1199(58.1)$ \\
\hline The Arabian Peninsula & $392(19.1)$ \\
\hline Iraq & $300(14.6)$ \\
\hline Egypt & $138(6.7)$ \\
\hline Turkey & $22(1.0)$ \\
\hline Iran & $10(0.5)$ \\
\hline \multicolumn{2}{|l|}{ Academic level, $n$ (\%) } \\
\hline Uneducated & $46(2.2)$ \\
\hline Pre-university study & $389(18.9)$ \\
\hline University study & $1495(72.5)$ \\
\hline Postgraduate & $131(6.4)$ \\
\hline \multicolumn{2}{|l|}{ Field of study, $\mathrm{n}(\%)$} \\
\hline Medical or health field & $784(38)$ \\
\hline Non-medical or health field & $1277(62)$ \\
\hline \multicolumn{2}{|l|}{ Field of work, $\mathrm{n}(\%)$} \\
\hline Medical or health field & $290(14)$ \\
\hline Non-medical or health field & $1771(86)$ \\
\hline $\begin{array}{l}\text { Participants infected previously with COVID- } \\
19, \mathrm{n}(\%)\end{array}$ & $61(3.0)$ \\
\hline $\begin{array}{l}\text { Participants who are committed to } \\
\text { quarantine in their home, } n(\%)\end{array}$ & $1847(89.6)$ \\
\hline
\end{tabular}




\begin{tabular}{|l|c|}
\hline \multicolumn{2}{|c|}{$\begin{array}{l}\text { Table 2. Sources of information about COVID-19 among } \\
\text { the study participants ( } \mathrm{n}=2061)\end{array}$} \\
\hline \multicolumn{1}{|c|}{ Source } & Percent \\
\hline Other & 9.4 \\
\hline Social media & 41.2 \\
\hline Visual and audible media & 35.2 \\
\hline Public's conversation & 13.9 \\
\hline WHO reports & 0.3 \\
\hline
\end{tabular}

\section{RESULTS}

Participants' characteristics are shown in Table 1. The majority of participants were females ( $n=1394,67.6 \%)$. A large fraction of them was from urban areas $(n=1896,92 \%)$. More than half ( $n=1199,58.1 \%$ ) were from countries of The Levant, followed by participants from The Arabian Peninsula ( $n=392,19.1 \%)$, Iraq ( $n=300,14.6 \%)$ and Egypt $(n=138,6.7 \%)$. About three-quarters of participants were undergraduate students ( $n=1495,72.5 \%)$. Only $38 \%$ of participants $(n=784)$ studied a specialty in the medical and health field and a lower proportion (14\%) worked in the health departments. Only 61 participants $(3.0 \%)$ reported to have been infected by the COVID-19. Most of participants $(n=1847,89.6 \%)$ were committed to quarantine at home.

Participants' sources of information about the COVID-19 pandemic (Table 2) showed that the social media platforms were the most common sources of information (41.2\%), followed by visual and audible media (35.2\%). Unexpectedly, the world health organization (WHO) reports were reported to be the least common source of information (0.3\%). About tenth of those included in the study $(9.4 \%)$ clarified alternative sources for their information.

Participants' knowledge and beliefs about COVID-19 pandemic revealed interesting results as outlined in Table 3. A majority of participants believed in the existence of COVID-19 pandemic (89.6\%), but not in the seriousness of the disease (13.7\%). Only a third of participants (37.0\%) did not believe that COVID-19 pandemic is a biological weapon. There were 1611 (78.2\%) participants who correctly knew
Table 4. The proportion of study participants who expressed agreement about the psychological effects of COVID-19 $(n=2061)$

\begin{tabular}{|l|c|}
\hline \multicolumn{1}{|c|}{ Psychological effect } & Percent \\
\hline Worried about family health & 92.2 \\
\hline Afraid to visit crowded places & 85 \\
\hline Anxious due to fake news & 80.7 \\
\hline Concerned about work & 80 \\
\hline confident in control measures & 50.4 \\
\hline Panic of touching anything & 43.4 \\
\hline
\end{tabular}

that COVID-19 can affect children. About a half of the participants did not know the effect of antihypertensive medications (52.5\%) and Hydroxychloroquine (46.5\%) on the COVID-19 infection. More than $80 \% \quad(n=1663)$ responded that the symptoms of COVID-19 infection might disappear in some cases while $11 \%(n=227)$ of participants responded with I do not know. And more than $78 \%$ $(n=1623)$ responded that they don't use a mask for more than once, in contrary to $14.6 \%(n=301)$ of participants who reported that they do were a mask more than one time. Moreover, the majority of participants knew the isolation period (a period of 14 days) of infected patients $(89.9 \%$, $\mathrm{n}=1852$ ), who were the most vulnerable group of people to become infected $(85.6 \%, n=1765)$, and methods of transmission of the virus $(89.5 \%, \mathrm{n}=1844)$.

The psychological effect of Coronavirus COVID-19 This section depicted the psychological effects of the ongoing pandemic among the participants. The vast majority (85\%, $\mathrm{n}=1751$ ) of participants were afraid of visiting crowded places and $64 \%(n=1320)$ reported fear of leaving their homes. Almost all participants $(92.2 \%, n=1901)$ expressed concerns about safety of their families. And $46 \%(n=945)$ of those questioned expressed their fear of getting infected with the virus even without leaving their homes, where $80 \%(n=1649)$ reported their concern if a family member walks out. The vast majority $80 \%(n=1664)$ agreed that the fake news on social media caused panic among the public and $61.5 \% \quad(n=1268)$ reported that they believe the situation is not as bad as portrayed by the media (Table 4). As well as the response of individuals regarding the government's-imposed safety measures, including curfews,

\begin{tabular}{|l|c|c|}
\hline \multicolumn{1}{|c|}{ Table 3. Assessment of study participants' knowledge and believes about COVID-19 pandemic ( $\mathrm{n}=2061)$} \\
\cline { 2 - 3 } & \multicolumn{2}{c|}{ Answers, $\mathbf{n}(\%)$} \\
\hline COVID-19 pandemic is a real fact & $1834(89.0)$ & $21(1.0)$ \\
\hline COVID-19 is seriousness & $282(13.7)$ & $148(7.2)$ \\
\hline COVID-19 is a biological weapon & $763(37.0)$ & $21(1.0)$ \\
\hline Symptoms of COVID-19 & $849(41.2)$ & $123(6.0)$ \\
\hline Effectiveness of hydroxychloroquine & $708(34.4)$ & $958(46.5)$ \\
\hline Effectiveness of saline solution & $588(28.5)$ & $742(36)$ \\
\hline The impact of climate on COVID-19 & $623(30.2)$ & $471(22.9)$ \\
\hline Method of COVID-19 spread & $1805(87.6)$ & $127(6.2)$ \\
\hline COVID-19 can affect children & $1611(78.2)$ & $200(9.7)$ \\
\hline The incubation period of COVID-19 & $1476(71.6)$ & $300(14.6)$ \\
\hline The risk of antihypertensive in infection with COVID-19 & $425(20.6)$ & $1083(52.5)$ \\
\hline Some COVID-19 infected cases are asymptomatic & $1663(80.7)$ & $227(11.0)$ \\
\hline All COVID-19 cases end with death & $1511(73.3)$ & $167(8.1)$ \\
\hline Infection methods & $1844(89.5)$ & $123(6.0)$ \\
\hline The most vulnerable group & $1765(85.6)$ & $118(5.7)$ \\
\hline Banned period of infected persons & $1852(89.9)$ & $109(5.3)$ \\
\hline Strengthening the immune system & $1593(77.3)$ & $199(9.7)$ \\
\hline Effectiveness of antibiotics & $675(32.8)$ & $692(33.6)$ \\
\hline Use of a single mask multiple times & $1623(78.7)$ & $137(6.6)$ \\
\hline All family members using the same mask & $1825(88.5)$ & $100(4.9)$ \\
\hline
\end{tabular}




\begin{tabular}{|c|c|}
\hline Behavior & Percent \\
\hline Using public facilities & 86.9 \\
\hline Social habits & 80.8 \\
\hline Personal habits & 76 \\
\hline Purchasing groceries & 50.2 \\
\hline Following news & 49.5 \\
\hline Work permit & 42.5 \\
\hline
\end{tabular}

social distances, and mandatory masks wearing was further investigated through this study. Approximately, the participants were evenly split (50\%) between those who trusted the current infection control measures and those who did not $(50 \%)$.

This section aimed to evaluate the impact of COVID-19 pandemic on participants' behavior in terms of abiding with the government recommendations about wearing masks, keeping social distancing and personal hygienic habits. The results are demonstrated in Table 5 .

The vast majority of participants avoided the use of public facilities (86.9\%) such as prayer places, gardens and buses. Approximately $87 \%$ of participants changed their social habits to new ones, such as hand shaking habits, limiting the physical contact with others and family reunions. Similarly, more than $75 \%$ changed their personal habits such as wearing masks, washing hands repeatedly, quitting smoking and carrying a hand sanitizer due to the COVID-19 pandemic. Notably, half of participants $(50.2 \%)$ were afraid of running out of food, so they purchased a lot of groceries. Less than half $(49.5 \%)$ however thought that the news about COVID-19 made them anxious, so they avoided watching, reading and listening to news. More than $40 \%$ applied for an annual leave in their workplace.

Participants were asked a multiple-choice question about the safety procedures they depended on to avoid getting infected with COVID-19.

Nutritional supplements, vitamin $C$ and vitamin $D$ took the vast proportion of participants' interest in order to protect themselves against coronavirus, with a percentage of $53.3 \%$. While depending on citrus drinks to strengthen their immune system came next, with a proportion of more than $36 \%$ of participants. Less than a third of participants $(27 \%)$ depended on increasing their vegetables intake, such as onion, garlic, and ginger. Additionally, about a quarter drank a decoction of various medicinal herbs, including one constituent or a combination. More than $20 \%$ did not take

\begin{tabular}{|l|r|}
\hline $\begin{array}{l}\text { Table 6. Safety precautions undertaken by participants to } \\
\text { avoid getting infected with COVID-19 }(\mathrm{n}=2061)\end{array}$ \\
\hline \multicolumn{1}{|c|}{ Safety precaution } & \multicolumn{1}{c|}{ Percent } \\
\hline Nutritional supplements and vitamins & 53.3 \\
\hline Citrus & 36.5 \\
\hline Vegetables (onion, garlic and ginger) & 27.3 \\
\hline Medicinal herbs & 23.7 \\
\hline Medicines (antipyretics and decongestants) & 13.6 \\
\hline Do nothing & 21 \\
\hline Other & 1.8 \\
\hline
\end{tabular}

any special measures to avoid getting infected with COVID19 (Table 6).

Overall, the participants who worked in a medical field tended to have better knowledge in evaluating drugs for Coronavirus disease, such as Hydroxychloroquine, and the risk of specific antihypertensive drugs during an infection with the Coronavirus compared to those from outside the medical field (Table 7). On the other hand, participants who had worked in a non-medical field were 1.5-2 times more likely to answer 'I don't know' than the participants who had worked in a medical field on method of Corona virus spread and effectiveness of antibiotics ( $p$-value $<0.05$ ).

\section{DISCUSSION}

This is the first study to use an e-survey designed to collect data from the Middle East countries revealing interesting changes taking place in the area regarding the COVID-19 pandemic. These changes touched on the knowledge of people, in addition to their beliefs and behaviour. We identified reasons that could be responsible for such changes. The resources of information participants used to enrich their information about the pandemic and its progress.

The media, and in particular the social platforms, played the major role in the awareness of people regarding the pandemic. Reporting the casualties and death rates from the different areas around the world was a major attracting point of the public's attention, reflecting the newcomer illness and its seriousness. This was not surprising, as other studies from around the world reported that social platforms, such as the WhatsApp and Facebook, and news media were the most utilized sources for public information gathering regarding the COVID-19 pandemic. $^{23-}$

${ }^{25}$ Interestingly, in middle eastern countries, such as Saudi Arabia and Jordan, social platforms were used by the Ministries of Health to communicate and engage the public in the preventative and control measures against COVID-

Table 7. Assessment knowledge regarding corona virus pandemic of participants in the medical/ health related field of work compared to participants from outside the medical/ health field $(n=2061)$

\begin{tabular}{|c|c|c|c|c|c|}
\hline \multirow{3}{*}{ Statements with p-value $<0.05$} & \multicolumn{5}{|c|}{ Answers, n (\%) } \\
\hline & \multicolumn{2}{|c|}{ Medical/ health field $(n=290)$} & \multicolumn{2}{|c|}{ Non-Medical/ health field $(n=1771)$} & \multirow{2}{*}{ p-value } \\
\hline & Correct answer & I do not know & Correct answer & I do not know & \\
\hline Effectiveness of Hydroxychloroquine & $128(44.1)$ & $87(30.0)$ & $580(32.7)$ & $871(49.2)$ & $<0.001$ \\
\hline Effectiveness of saline solution & $92(31.7)$ & $81(27.9)$ & $496(28.0)$ & $661(37.3)$ & 0.008 \\
\hline The impact of climate on Corona & $101(34.8)$ & $48(16.6)$ & $522(29.5)$ & $423(23.9)$ & 0.015 \\
\hline Method of Corona virus spread & $258(89.0)$ & $9(3.1)$ & $1547(87.4)$ & $118(6.7)$ & 0.035 \\
\hline The incubation period of Coronavirus & $223(76.9)$ & $25(8.6)$ & $1253(70.8)$ & $275(15.5)$ & 0.008 \\
\hline The risk of antihypertensive & $74(25.5)$ & $109(37.6)$ & $351(19.8)$ & $974(55.0)$ & $<0.001$ \\
\hline Banned period of infected & $253(87.2)$ & $11(3.8)$ & $1599(90.3)$ & $98(5.5)$ & 0.001 \\
\hline Strengthening the immune system & $213(73.4)$ & $20(6.9)$ & $1380(77.9)$ & $179(10.1)$ & 0.001 \\
\hline Effectiveness of antibiotics & $104(35.9)$ & $64(22.1)$ & $571(32.2)$ & $628(35.5)$ & $<0.001$ \\
\hline
\end{tabular}


$19 .^{16,26}$ No significant correlation between different predictors, including age, gender and educational level with participants knowledge was found in this study. However, working in the medical/health-related field was found to have a significant association with better knowledge among participants ( $p$-value<0.05). Other studies reported that age, educational level, and income had significant association with people's knowledge regarding COVID$19 .^{27,28}$

COVID-19 came bringing with it changes that touched every part of people's life. People reacted to the pandemic by changing many of their habits, like staying away from gatherings in common places, including transports and holy mosques. The COVID -19 behavioural impact was presented not only in practicing a high level of self-isolation, but also by keeping physical distancing and other initiating safety measures. $^{29}$ Similar to our study findings, various behaviours were observed among individuals participating in other studies, following the governments recommendations about wearing masks, keeping social distancing, personal hygienic habits and washing hands in order to halt the spread of the disease and to protect themselves. ${ }^{29,30}$ These measures, to a recent era, were unthinkable to happen. Such changes also impacted jobs, future welfare, and food supply, represented by the illpractices of stockpiling foods, staying at home to avoid being infected by work colleagues, increasing the anxiety level in the society. ${ }^{31}$

As for the psychological impact of COVID-19 on individuals, the vast majority of our study participants reported fear and safety concerns due to the pandemic. Similarly, a research study conducted in the United States, China and United Kingdom, showed an increase in prevalence of panic and anxiety disorders among people due to the increased levels of social and economic tension, unemployment, psychological stress, and fear. ${ }^{32-34}$ Likewise, among Arab countries, various studies reported an increased level of mental and psychological stresses due to the pandemic. ${ }^{35-38}$ These results highlight the need of implementing a psychological intervention to those in need, in order to lessen the impact of this pandemic on individuals' mental and physical health.

It has been well acknowledged that the COVID-19 pandemic posed serious health, social and psychological challenges, affecting the public's physical and mental health, as well as the individual's financial economics. ${ }^{29,31,39}$ Such detrimental consequences could be behind why twothirds of the people in the Middle East (63\%) reported via this study that they believe that the Coronavirus is a biological weapon. Such believe limits precautionary measures to prevent the infection, thus could lead to increasing the number of infected people. On the other hand, a lower percentage (13.7\%) of participants did not believe in the seriousness of the disease, which in turn, presents another challenge to policy makers to limit the spread of the virus and increase the awareness of the disease. In contrary to this, findings from studies from other areas around the world including US and Canada reported that the majority of respondents perceived COVID-19 as a very serious problem imposing major changes to their plans and lifestyle. ${ }^{29,40}$ On the positive side of things, the pandemic played a positive role in increasing interests in good habits in terms of food and exercise practices. ${ }^{41}$ The study showed that people became more interested in good eating habits and diets of supplementary additives, such as vitamins and medicinal herbs. However, trends toward unfavourable dietary behaviours during the lockdown, such as increased caloric intake, reduced consumption of fruits and vegetables, and weight gain study was reported. ${ }^{42,43}$ In contrary to our findings, a study in the United Arab Emirates (UAE) reported a shift towards unhealthy dietary patterns among participants during the pandemic. ${ }^{44}$ In addition to physical exhaustion, emotional exhaustion, irritability, tension and sleeping disturbances have been reported. ${ }^{44}$

Yet, in light of the spread of false information, people took wrong turns with regards to practices in food intake, health in general and work, which require immediate correction measures by governments. Governments of the region need to provide trust-worthy sources for information that assures clarity and reliability. ${ }^{14}$ This is not the first study to shed light on this major issue. Misleading information was reported by participants in other studies as well, suggesting that official health authorities and governments should consider mainstream media and social platforms as an essential source to convey accurate information. ${ }^{29,45}$

People's insecurity due to the pandemic was not supported by governments' efforts at the same level. People needed more assurance to stop wrong-practices, which would require more investments in the different health sectors and unemployment compensation. ${ }^{46}$ This practice will help ease the fear of the unknown future, which would otherwise preserve the increased anxiety and mental illness problems. $^{9}$

Thus, there is a critical need for the implementation of governmental strategies $s$ to control the outbreak of the virus by continuous providing the needed physical and psychological help for the individuals. While many hospitals and ICUs treating COVID-19 patients are slowly reaching capacity, the governments should raise the preparedness of health sectors of available laboratories, technical and working staff and, train and seek assistance to provide the needed health care services during this pandemic. ${ }^{47}$ For example, in Jordan additional measures have been reintroduced including Friday lockdowns and extended curfew hours. As well as the government is moving forward to accelerate the vaccination programme against COVIID$19 .^{48}$ Indeed, the role of pharmacists is highly crucial and should be incorporated into the pandemic's plans as frontline healthcare professionals. Pharmacist guideline was released by the International Pharmaceutical Federation (FIP) to clarify the required coronavirus information for pharmacists and the pharmacy workforce including educating the public on infection control and preventive measures to reduce transmission which was adapted by governments in middle east. ${ }^{49-51}$

The development and approval of several COVID-19 vaccines could also help in resolving the pre-mentioned issues. ${ }^{52-54}$ The healthcare policy makers can call for an optimization of evidence-based vaccine delivery strategies, aligning with public's perceptions, and safety concerns (e.g. adverse effects and cost) to influence vaccination acceptance among people, halting the spreading of the 
virus. $^{55}$ It has been reported that many individuals are doubtful and skeptical of receiving the new COVID-19 vaccine. $^{56}$ Thus, a reliable relationship between governments and individuals is crucial to enhance their willingness to receive the COVID-19 vaccine and to overcome the burden of spreading this disease.

\section{Limitations}

Although the questionnaire underwent face and internal validity by experts, the internal validity for the psychological effect of COVID-19 section had a low internal consistency of Cronbach's alpha $=0.62$, future studies can look to improve the content validity of this section by updating some of the questions in this section.

\section{CONFLICT OF INTEREST}

The authors declare that no financial or other potential conflicts of interest exist.

\section{FUNDING}

None.

\author{
AUTHOR ROLES (CRediT) \\ Conceptualization: HA, IAB. \\ Formal analysis: IAB. \\ Methodology: HA, IAB. \\ Resources: EEAJ, AA. WMK. \\ Supervision: HA. \\ Validation: IAB. \\ Writing - original draft: EEAJ, AA, WMK. \\ Writing - review \& editing: HA, IAB.
}

\section{References}

1. Wang C, Horby PW, Hayden FG, Gao GF. A novel coronavirus outbreak of global health concern [published correction appears in Lancet. 2020 Jan 29;:]. Lancet. 2020;395(10223):470-473. https://doi.org/10.1016/s0140-6736(20)30185-9

2. Epidemiology Working Group for NCIP Epidemic Response, Chinese Center for Disease Control and Prevention. Zhonghua Liu Xing Bing Xue Za Zhi. 2020;41(2):145-151. https://doi.org/10.3760/cma.j.issn.0254-6450.2020.02.003

3. World Health Organization. Risk communication and community engagement readiness and response to coronavirus disease (COVID-19): interim guidance, https://apps.who.int/iris/bitstream/handle/10665/331513/WHO-2019-nCoV-RCCE2020.2-eng.pdf? sequence $=1$ \&isAllowed=y (accessed Jan 12 2021).

4. World Health Organization. Coronavirus disease ( COVID-19). https://www.who.int/emergencies/diseases/novelcoronavirus-2019 (accessed Jan 12 2021).

5. Pandey SJJCMR. Gupta A. Bhansali R, Balhara S, Katira P, Fernandes G. Corona virus (COVID-19) awareness assessment-a survey study amongst the Indian population. J Clin Med Res. 2020;2(4):1-11. https://doi.org/10.37191/Mapsci-2582-4333-2(3)-041

6. Huang C, Wang Y, Li X, et al. Clinical features of patients infected with 2019 novel coronavirus in Wuhan, China. Lancet. 2020;395(10223):497-506. https://doi.org/10.1016/s0140-6736(20)30183-5

7. Wang D, Hu B, Hu C, et al. Clinical Characteristics of 138 Hospitalized Patients With 2019 Novel Coronavirus-Infected Pneumonia in Wuhan, China [published correction appears in JAMA. 2021 Mar 16;325(11):1113]. JAMA. 2020;323(11):1061-1069. https://doi.org/10.1001/jama.2020.1585

8. Masoud AT, Zaazouee MS, Elsayed SM, et al. KAP-COVIDGLOBAL: a multinational survey of the levels and determinants of public knowledge, attitudes and practices towards COVID-19. BMJ Open. 2021;11(2):e043971. https://doi.org/10.1136/bmjopen-2020-043971

9. Giacalone A, Rocco G, Ruberti E. Physical Health and Psychosocial Considerations During the Coronavirus Disease 2019 Outbreak. Psychosomatics. 2020;61(6):851-852. https://doi.org/10.1016/i.psym.2020.07.005

10. Tachfouti N, Slama K, Berraho M, Nejjari C. The impact of knowledge and attitudes on adherence to tuberculosis treatment: a case-control study in a Moroccan region. Pan Afr Med J. 2012;12:52.

11. Basheti IA, Nassar R, Barakat M, et al. Pharmacists' readiness to deal with the coronavirus pandemic: Assessing awareness and perception of roles. Res Social Adm Pharm. 2021;17(3):514-522. https://doi.org/10.1016/i.sapharm.2020.04.020

12. Balkhi F, Nasir A, Zehra A, Riaz R. Psychological and Behavioral Response to the Coronavirus (COVID-19) Pandemic. Cureus. 2020;12(5):e7923. https://doi.org/10.7759/cureus.7923

13. Lau JT, Yang X, Tsui H, Kim JH. Monitoring community responses to the SARS epidemic in Hong Kong: from day 10 to day 62. J Epidemiol Community Health. 2003;57(11):864-870. https://doi.org/10.1136/jech.57.11.864

14. Kebede $\mathrm{Y}$, Yitayih Y, Birhanu Z, Mekonen S, Ambelu A. Knowledge, perceptions and preventive practices towards COVID-19 early in the outbreak among Jimma university medical center visitors, Southwest Ethiopia. PLoS One. 2020;15(5):e0233744. https://doi.org/10.1371/journal.pone.0233744

15. Moradzadeh R, Nazari J, Shamsi M, Amini S. Knowledge, Attitudes, and Practices Toward Coronavirus Disease 2019 in the Central Area of Iran: A Population-Based Study. Front Public Health. 2020;8:599007. https://doi.org/10.3389/fpubh.2020.599007

16. Al-Hanawi MK, Angawi K, Alshareef N, et al. Knowledge, Attitude and Practice Toward COVID-19 Among the Public in the Kingdom of Saudi Arabia: A Cross-Sectional Study. Front Public Health. 2020;8:217. https://doi.org/10.3389/fpubh.2020.00217 
17. COVID-19 Knowledge, Attitudes and Practices (KAP) Survey: Northwest Syria. https://reliefweb.int/report/syrian-arabrepublic/covid-19-knowledge-attitudes-and-practices-kap-survey-northwest-syria-5 (accessed Jan 12, 2021).

18. Qutob N, Awartani F, Asia M, Khader IA. Knowledge and practices towards COVID-19 among Palestinians during the COVID-19 outbreak: A second round cross-sectional survey. https:/www.medrxiv.org/content/10.1101/2020.10.13.20211888v1 (accessed Jan 12, 2021).

19. Sallam M, Dababseh D, Yaseen A, et al. COVID-19 misinformation: Mere harmless delusions or much more? A knowledge and attitude cross-sectional study among the general public residing in Jordan. PLoS One. 2020;15(12):e0243264. https://doi.org/10.1371/journal.pone.0243264

20. Abdel Wahed WY, Hefzy EM, Ahmed MI, Hamed NS. Assessment of Knowledge, Attitudes, and Perception of Health Care Workers Regarding COVID-19, A Cross-Sectional Study from Egypt. J Community Health. 2020;45(6):1242-1251. https://doi.org/10.1007/s10900-020-00882-0

21. Iorfa SK, Ottu IFA, Oguntayo R, et al. COVID-19 Knowledge, Risk Perception, and Precautionary Behavior Among Nigerians: A Moderated Mediation Approach. Front Psychol. 2020;11:566773. https://doi.org/10.3389/fpsyg.2020.566773

22. Olapegba PO, lorfa SK, Kolawole SO, et al. Survey data of COVID-19-related Knowledge, Risk Perceptions and Precautionary Behavior among Nigerians. Data Brief. 2020;30:105685. https://doi.org/10.1016/j.dib.2020.105685

23. Olum R, Chekwech G, Wekha G, Nassozi DR, Bongomin F. Coronavirus Disease-2019: Knowledge, Attitude, and Practices of Health Care Workers at Makerere University Teaching Hospitals, Uganda. Front Public Health. 2020;8:181. https://doi.org/10.3389/fpubh.2020.00181

24. Ali KF, Whitebridge S, Jamal MH, Alsafy M, Atkin SL. Perceptions, Knowledge, and Behaviors Related to COVID-19 Among Social Media Users: Cross-Sectional Study. J Med Internet Res. 2020;22(9):e19913. https://doi.org/10.2196/19913

25. Kakemam E, Ghoddoosi-Nejad D, Chegini Z, et al. Knowledge, Attitudes, and Practices Among the General Population During COVID-19 Outbreak in Iran: A National Cross-Sectional Online Survey. Front Public Health. 2020;8:585302. https://doi.org/10.3389/fpubh.2020.585302

26. Al-Dmour H, Masa'deh R, Salman A, Abuhashesh M, Al-Dmour R. Influence of Social Media Platforms on Public Health Protection Against the COVID-19 Pandemic via the Mediating Effects of Public Health Awareness and Behavioral Changes: Integrated Model. J Med Internet Res. 2020;22(8):e19996. https://doi.org/10.2196/19996

27. Zhong BL, Luo W, Li HM, et al. Knowledge, attitudes, and practices towards COVID-19 among Chinese residents during the rapid rise period of the COVID-19 outbreak: a quick online cross-sectional survey. Int J Biol Sci. 2020;16(10):17451752. https://doi.org/10.7150/ijbs.45221

28. Nooh HZ, Alshammary RH, Alenezy JM, et al. Public awareness of coronavirus in Al-Jouf region, Saudi Arabia [published online ahead of print, 2020 Feb 13]. Z Gesundh Wiss. 2020;1-8. https://doi.org/10.1007/s10389-020-01209-y

29. Parsons Leigh J, Fiest K, Brundin-Mather R, et al. A national cross-sectional survey of public perceptions of the COVID19 pandemic: Self-reported beliefs, knowledge, and behaviors. PLoS One. 2020;15(10):e0241259. https://doi.org/10.1371/journal.pone.0241259

30. Abdelrahman M. Personality Traits, Risk Perception, and Protective Behaviors of Arab Residents of Qatar During the COVID-19 Pandemic. Int J Ment Health Addict. 2020; [ahead of print]. https://doi.org/10.1007/s11469-020-00352-7

31. Murthy RS. COVID-19 pandemic and emotional health: Social psychiatry perspective. Ind J Soc Psychyat. 2020;36(5):24. . https://doi.org/10.4103/ijsp.ijsp 29320

32. Fitzpatrick KM, Harris C, Drawve G. Living in the midst of fear: Depressive symptomatology among US adults during the COVID-19 pandemic. Depress Anxiety. 2020;37(10):957-964. https://doi.org/10.1002/da.23080

33. Qiu J, Shen B, Zhao M, Wang Z, Xie B, Xu Y. A nationwide survey of psychological distress among Chinese people in the COVID-19 epidemic: implications and policy recommendations [published correction appears in Gen Psychiatr. 2020 Apr 27;33(2):e100213corr1]. Gen Psychiatr. 2020;33(2):e100213. https://doi.org/10.1136/gpsych-2020-100213

34. Pierce M, Hope H, Ford T, et al. Mental health before and during the COVID-19 pandemic: a longitudinal probability sample survey of the UK population. Lancet Psychiatry. 2020;7(10):883-892. https://doi.org/10.1016/s2215$\underline{0366(20) 30308-4}$

35. El-Zoghby SM, Soltan EM, Salama HM. Impact of the COVID-19 Pandemic on Mental Health and Social Support among Adult Egyptians. J Community Health. 2020;45(4):689-695. https://doi.org/10.1007/s10900-020-00853-5

36. Alkhamees AA, Alrashed SA, Alzunaydi AA, Almohimeed AS, Aljohani MS. The psychological impact of COVID-19 pandemic on the general population of Saudi Arabia. Compr Psychiatry. 2020;102:152192. https://doi.org/10.1016/i.comppsych.2020.152192

37. Shuwiekh HAM, Kira IA, Sous MSF, et al. The differential mental health impact of COVID-19 in Arab countries [published online ahead of print, 2020 Nov 2]. Curr Psychol. 2020;1-15. https://doi.org/10.1007/s12144-020-01148-7

38. Badahdah A, Khamis F, Al Mahyijari N, et al. The mental health of health care workers in Oman during the COVID-19 pandemic [published online ahead of print, 2020 Jul 8]. Int J Soc Psychiatry. 2020;20764020939596. https://doi.org/10.1177/0020764020939596

39. Vijai C, Suryalakshmi SJCC, Special Issue. Awareness, Attitudes, and Practices Related to Coronavirus (COVID-19) Pandemic among Public in Chennai City, India. Cape Comorin. 2020;2(5):27-37.

40. Bailey SC, Serper M, Opsasnick L, et al. Changes in COVID-19 Knowledge, Beliefs, Behaviors, and Preparedness Among High-Risk Adults from the Onset to the Acceleration Phase of the US Outbreak. J Gen Intern Med. 2020;35(11):3285-3292. https://doi.org/10.1007/s11606-020-05980-2

41. Moro M, Vigezzi GP, Capraro M, et al. 2019-novel coronavirus survey: knowledge and attitudes of hospital staff of a large Italian teaching hospital. Acta Biomed. 2020;91(3-S):29-34. https://doi.org/10.23750/abm.v91i3-s.9419

42. Deschasaux-Tanguy M, Druesne-Pecollo N, Esseddik $Y$, et al. Diet and physical activity during the coronavirus disease 2019 (COVID-19) lockdown (March-May 2020): results from the French NutriNet-Santé cohort study. Am J Clin Nutr. 2021;113(4):924-938. https://doi.org/10.1093/ajcn/nqaa336 
43. Zachary Z, Brianna F, Brianna L, et al. Self-quarantine and weight gain related risk factors during the COVID-19 pandemic. Obes Res Clin Pract. 2020;14(3):210-216. https://doi.org/10.1016/i.orcp.2020.05.004

44. Cheikh Ismail L, Osaili TM, Mohamad MN, et al. Eating Habits and Lifestyle during COVID-19 Lockdown in the United Arab Emirates: A Cross-Sectional Study. Nutrients. 2020;12(11):3314. https://doi.org/10.3390/nu12113314

45. Kouzy R, Abi Jaoude J, Kraitem A, et al. Coronavirus Goes Viral: Quantifying the COVID-19 Misinformation Epidemic on Twitter. Cureus. 2020;12(3):e7255. https://doi.org/10.7759/cureus.7255

46. Health Communication Capacity Collaborative GoLMoH. National Knowledge, Attitudes, and Practices (KAP) Survey on Ebola Virus Disease in Liberia. https://healthcommcapacity.org/wp-content/uploads/2017/07/Liberia KAP-II Report FinalMay-2017 HC3.pdf (accessed Apr 30 2021).

47. Boufkhed S, Harding R, Kutluk T, Husseini A, Pourghazian N, Shamieh O. What Is the Preparedness and Capacity of Palliative Care Services in Middle-Eastern and North African Countries to Respond to COVID-19? A Rapid Survey. J Pain Symptom Manage. 2021;61(2):e13-e50. https://doi.org/10.1016/i.jpainsymman.2020.10.025

48. Refugees UNHCf. UNHCR Jordan COVID-19 response. https://data2.unhcr.org/en/documents/details/85614 (accessed Apr 30 2021).

49. FIP. Coronavirus 2019-nCoV outbreak: Information and interim guidelines for pharmacists and the pharmacy workforce. https://www.fip.org/files/content/priority-areas/coronavirus/FIP Webinar Coronavirus response 20200210.pdf (accessed Apr 30 2021)

50. Basheti IA, Nassar R, Barakat M, et al. Pharmacists' perceived barriers towards delivering their emergency roles during the COVID-19 pandemic and perceived policymakers' responsibilities. J Pharm Policy Pract. 2020;13:62. https://doi.org/10.1186/s40545-020-00254-y

51. Kretchy IA, Asiedu-Danso M, Kretchy JP. Medication management and adherence during the COVID-19 pandemic: Perspectives and experiences from low-and middle-income countries. Res Social Adm Pharm. 2021;17(1):2023-2026 https://doi.org/10.1016/i.sapharm.2020.04.007

52. Administration USFaD. FDA takes key action in fight against COVID-19 by issuing emergency use authorization for first COVID-19 vaccine. https://www.fda.gov/news-events/press-announcements/fda-takes-key-action-fight-against-covid-19issuing-emergency-use-authorization-first-covid-19 (accessed Jan 12 2021).

53. Administration USFaD. FDA takes additional action in fight against COVID-19 by issuing emergency use authorization for second COVID-19 vaccine. https://www.fda.gov/news-events/press-announcements/fda-takes-additional-action-fightagainst-covid-19-issuing-emergency-use-authorization-second-covid (accessed Jan 12 2021).

54. European Centre for Disease Prevention and Control. First COVID-19 vaccine authorised for use in the European Union. https://www.ecdc.europa.eu/en/news-events/first-covid-19-vaccine-authorised-use-european-union (accessed Jan 12 2021).

55. Weintraub RL, Subramanian L, Karlage A, Ahmad I, Rosenberg J. COVID-19 Vaccine To Vaccination: Why Leaders Must Invest In Delivery Strategies Now. Health Aff (Millwood). 2021;40(1):33-41. https://doi.org/10.1377/hlthaff.2020.01523

56. Coustasse A, Kimble C, Maxik K. COVID-19 and Vaccine Hesitancy: A Challenge the United States Must Overcome. J Ambul Care Manage. 2021;44(1):71-75. https://doi.org/10.1097/jac.0000000000000360 